\title{
LA PROHIBICIÓN DE PESCAR ATÚN EN D. 8,4,13 PR. (UlP., 6 OPIN.): ¿UNA SERVIDUMBRE CONSTITUIDA “PACTIONIBUS ET STIPULATIONIBUS"?
}

["Tuna Fishing Ban in D. 8,4,13 pr. (Ulp., 6 opin.): a Servitude Created 'pactionibus et stipulationibus'?"]

\author{
Rosa M. Carreño SánChez* \\ Universidad de Girona, España
}

\section{RESUMEN}

El artículo trata sobre la naturaleza de la prohibición de pescar atún, impuesta al realizarse la compraventa de un fundo provincial. Concretamente, se intenta determinar si, en este caso, nos encontramos ante una servidumbre negativa, constituida pactionibus et stipulationibus, partiendo de la respuesta que ofrece Ulpiano en el caso concreto.

\section{Palabras Clave}

Servitutes - Constitución de servitutes pactionibus et stipulationibus - Pesca del atún.

\section{ABSTRACT}

This paper refers to the nature of the tuna fishing ban imposed upon the purchase and sale of a country side farm. Strictly speaking, we intend to know if, in this particular case, we are facing a negative servitude, formed on a pactionibus et stipulationibus basis, starting from the answer Ulpiano gives in this regard.

\section{KEYWORDS}

Servitutes - Formation of servitutes pactionibus et stipulationnibus - Tuna fishing.

Recibido el 29 DE JUNio y ACEPTADo el 22 DE JULIO DE 2011

* Profesora asociada de Derecho romano en la Facultad de Derecho de la Universidad de Gerona. Dirección postal: Campus de Montilivi s/n, E-17071 Girona, España. Correo electrónico: rosamaria.carreno@udg.edu. El contenido de este artículo fue presentado como comunicación en la 64a sesión de la SIHDA, celebrada en Barcelona desde el 28 de septiembre al 2 de octubre de 2010. 


\section{INTRODUCCIÓN}

En D.8,4,13 pr. (6 opin.), Ulpiano se ocupa de la compraventa de un fundo costero en la que se incluye una prohibición de pescar atún que afecta al comprador. El texto no ha dejado a la doctrina indiferente en ninguno de los casos, no sólo por la posibilidad de que la obra a la que pertenece el citado fragmento -los libri opinionum - pudiera no haber sido redactada por este jurista clásico tardío ${ }^{1}$ (o, incluso, que hubiera visto la luz en época postclásica), sino, más bien, porque el texto parece referirse a una servidumbre constituida pactionibus et stipulationibus. El principal punto de debate giraría, así pues, entorno a la posibilidad de que la prohibición de ejercer la pesca del atún, en este caso, pueda tratarse del contenido de una servidumbre negativa constituida pactionibus et stipulationibus ${ }^{2}$. Dice el texto: "Venditor fundi Geroniani fundo Botriano, quem retinebat, legem dederat,

${ }^{1}$ La autoría de esta obra ha sido objeto de un vivo debate en la doctrina: Santalucia la atribuye sin duda a Ulpiano, opinión diametralmente opuesta a la de Schulz, Provera, Liebs u Honoré. Para Schulz, esta obra habría sido redactada en época postclásica, partiendo de los comentarios de Ulpiano al edicto, pues parece que la sistemática empleada por su autor sería la misma que la del edicto pretorio, como bien habría observado Lenel en Palingenesia iuris civilis, II, $\$ 2296$, p. 1001 n. 2 . Hallebeek también ha planteado sus dudas acerca de que Ulpiano sea su autor, sin llegar a excluir del todo esta idea, pues data la obra como perteneciente a época clásica tardía. Considera, asimismo, que sería necesario realizar un análisis crítico de la obra, en el que se combinen el estudio exhaustivo de las cuestiones lingüísticas, así como el estudio de las cuestiones de fondo y de metodología que usa el jurista en cada fragmento. Véase: Schulz, Fritz, Storia della giurisprudenza romana (Florencia, 1968), pp. 324 ss.; SANTALUCIA, Bernardo, I libri "opinionum" di Ulpiano (Milano, 1971), I, p. 1 ss.; Provera, Giuseppe, Servitù prediali ed obbligazioni propter rem, en Studi in onore di Edoardo Volterra (Milano, 1971), II, p. 17 [http://www.ledonline.it/rivistadirittoromano/allegatiproveraservitu.pdf]; LIEBS, Dieter, "Ulpiani opinionum libri VT', en TR., 41 (1973), pp. 279 ss.; Honoré, Anthony, Ulpian (Oxford, 1982), pp. 120 ss.; Hallebeek, Jan, Legal Problems Concerning a Draught of Tunny. Exegesis of D.8.4.13 pr., en TR., 55 (1987), p. 48; FINKENAUER, Thomas, Vererblichkeit und Drittwirkungen der Stipulatio im klassischen römischen Recht (Tübingen, 2010), p. 377.

${ }^{2}$ Véase: Franciosi, Gennaro, Il divieto della piscatio thynnaria: un'altra servitù prediale?, en RIDA., 49 (2002), p. 101-107; y más recientemente: PURPURA, Gianfranco, Servitus thynnos non piscandi (D.8.4.13 pr.), en D'IPpolito, Federico Maria (editor), Scritti per Gennaro Franciosi (Napoli, 2007), III, p. 2163-2174. Similarmente, entre la doctrina española: MoHino MaNRIQUE, Ana, Pactos en el contrato de compraventa en interés del vendedor (Madrid, 2006), p. 254 ss., aunque la autora defiende que la referencia final, concerniente a la stipulatio, es un añadido compilatorio (p. 255). El texto trataría un caso de aplicación de las pactiones et stipulationes, aunque con meros efectos obligatorios, de acuerdo con SANTALUCIA, Bernardo, cit. (n. 1), II, pp. 253 ss.; KASER, Max, Der Privatrechtsakt in der römischen Rechtsquellenlehre, en Festschrift für Franz Wieacker zum 70. Geburtstag (Göttingen, 1978), pp. 99 ss.; TalamanCA, Mario, Pubblicazioni pervenute alla Direzione, en BIDR., 91 (1998), pp. 909 ss. Sigue la opinión de Santalucia y Talamanca se plantea la posibilidad de la eficacia real de las pactiones et stipulationes en provincias (Gai. 2,31); FionentinI, Mario, Fiumi e mari nell'esperienza giuridica romana. Profili di tutela processuale e di inquadramento sistematico (Milano, 2003), p. 424 n. 85; PROVERA, Giuseppe, cit. (n. 1), p. 17. Especial mención merece el profundo estudio de este texto por parte de HAllebeEK, Jan, cit. (n. 1), p. 45, que presta más atención a la solución ofrecida por Ulpiano que a la presencia o no de las pactiones et stipulationes. Para este autor, el texto se referiría una obligación y no de una servidumbre, aunque, como veremos, dicha obligación se transmite a los sucesivos titulares del fundo Geroniano.. 
ne contra eum piscatio thynnaria exerceatur. Quamvis mari, quod natura omnibus patet, servitus imponi privata lege non potest, quia tamen bona fides contractus legem servari venditionis exposcit, personae possidentium aut in ius eorum succedentium per stipulationis vel venditionis legem obligantur.

El vendedor del fundo Geroniano estableció, a favor del fundo Botriano, fundo que él retuvo, la prohibición de pescar atún en perjuicio de este último predio. Aunque por una cláusula privada no es posible imponer una servidumbre sobre el mar, ya que, por naturaleza, el mar se encuentra a disposición de todo el mundo, no obstante, la buena fe del contrato exige que se respete dicha cláusula de la venta, de modo que las personas que poseen el fundo y sus sucesores queden obligados por la mencionada cláusula de la stipulatio o de la venta ${ }^{3}$. El caso expuesto por Ulpiano podría resumirse del siguiente modo: los fundos Geroniano y Botriano son fundos vecinos pertenecientes a un mismo sujeto. Estos fundos, por lo que puede inferirse del texto, están situados en la costa y tienen acceso directo al mar. Al realizarse la venta del fundo Geroniano, el vendedor impone una cláusula que beneficiaría al fundo Botriano, en virtud de la cual, el adquirente del fundo vendido debe abstenerse de practicar la pesca del atún en dicho predio -en concreto, se prohíbe la práctica de la pesca de atún que pudiera perjudicar al fundo Botriano ${ }^{4}$.

La inclusión de esta cláusula prohibitoria en la compraventa se explicaría por la actividad económica desarrollada sobre el fundo Botriano: la pesca del atún. Es posible que el vendedor quisiera evitar la más que probable competencia futura del fundo vecino, que también podría dedicarse a la misma actividad. El vendedor evitaría, de esta manera, posibles pérdidas económicas, así como las variaciones en los flujos migratorios del atún. En este sentido, Wacke 5 plantea muy acertadamente que la compraventa no tendría sólo por objeto el fundo Geroniano, sino que, de hecho, también se estaría refiriendo a la empresa de pesca existente en el predio, de ahí que al vendedor le interese incluir en la venta tal prohibición, incluso con vistas a evitar la perturbación de la paz y tranquilidad en el disfrute de su propio fundo ${ }^{6}$.

\footnotetext{
${ }^{3} \mathrm{Al}$ traducir el texto latino, hemos tenido en cuenta la traducción alemana de BeHRENDS, Okko y otros, Corpus iuris civilis. Text und Übersetzung (Auf der von Theodor Mommsen und Paul Krüger besorgten Textausgaben) (Heidelberg, 1990), II, p. 704.

${ }^{4}$ Precisamente, como nos advierte FranCIOSI, Gennaro, cit. (n. 2), p. 102, para entender cómo la pesca del atún en el fundo Geroniano podría hacerse en perjuicio del fundo Botriano, debe tenerse en cuenta las técnicas usadas en época romana para dicha actividad económica, que aún se encontrarían vigentes, en gran medida, en algunas zonas del Mediterráneo. La pesca del atún no se desarrolla solamente en alta mar, sino que requiere del avistamiento desde tierra de los bancos de atunes, que en muchos de los casos hallaban la muerte en las riberas del mar o en tierra, a través del uso de arpones o bastones. Véase, más abajo, $\$$ III 2.

${ }^{5}$ WACKE, Andreas, Wettbewerbsfreiheit und Konkurrenzverbotklauseln im antiken und modernen Recht, en ZSS., 99 (1982), p. 213.

${ }^{6}$ En contra de esta idea, PurPuRA, Gianfranco, cit. (n. 2), pp. 2.165 ss. Aunque resulte difícil conocer con exactitud cuál era la intención del vendedor, resulta extraño que el único caso de prohibición de ejercer la pesca del atún que se encuentra en el Digesto tenga que ver con un deseo de mantener la paz y tranquilidad en el fundo del vendedor. Tal prohibición claramente se justifica por motivos económicos, evitar un descenso de los ingentes ingresos que el negocio
} 
Como decíamos, la quaestio surgiría entorno a la naturaleza de esta prohibición, es decir, si podría considerarse o no una servidumbre y en qué medida el adquirente y sus sucesores podían quedar sujetos al cumplimiento de esta cláusula prohibitoria. El jurista sostiene que, en este supuesto, no puede entenderse que se constituya una servidumbre, en la cual el fundo Botriano sea el fundo dominante y el Geroniano el sirviente, debido a que no es posible constituir una servidumbre sobre el mar, pues se trata de un bien accesible a todo el mundo (res communis omnium). Ahora bien, y en atención a la buena fe del contrato de compraventa, entiende que sí puede decirse que el comprador quedaría vinculado por la cláusula prohibitoria de la venta o de la stipulatio. Y no sólo el comprador, pues Ulpiano también incluye a sus sucesores, sin especificar si se trata únicamente de los sucesores a título universal o también los sucesores a título particular -“personae possidentium aut in ius eorum succedentium", puntualización que, como veremos más adelante, ha dado lugar a multitud de interpretaciones y opiniones.

Esta última cuestión deviene más compleja si cabe -especialmente para la doctrina y no tanto para el jurista clásico tardío-, si se tiene en cuenta que los fundos Geroniano y Botriano son fundos provinciales -como puede extraerse de la referencia "personae possidentium" (cfr. Gai. 2, 7) 7 - y debido a que el jurista expresa que los sucesores quedarían obligados "per stipulationis vel venditionis legem", locución que parece recordar la constitución de servidumbres pactionibus et stipulationibus (Gai. 2,31).

Erróneamente, este recuerdo a las pactiones et stipulationes ha conducido a una parte de la doctrina ${ }^{8}$ a afirmar que nos encontramos ante un ejemplo de servidumbre de no pescar atún constituida a través de este negocio, pese a que Ulpiano expresamente indica que no es posible imponer una servidumbre sobre el mar. Desde otro sector doctrinal se defiende que, en este caso, nunca pudo constituirse una servidumbre, pero no precisamente siguiendo el razonamiento de Ulpiano, sino debido a la mera eficacia obligacional de las pactiones et stipulationes, lo que podría observarse en la referencia "personae possidentium aut in ius eorum succedentium per stipulationis vel venditionis legem obligantur", que, además de hablar de una obligación (obligantur), indicaría que el comprador y sus herederos serían las únicas personas sujetas a la prohibición -como bien habrían visto los glosadores y comentaristas (véase, más abajo, el $\$$ IV).

Creemos que es posible realizar una nueva lectura de la solución adoptada por Ulpiano, que se aleje de estas dos posturas tan extremas y se acerque más a la solución ofrecida por el jurista en este caso concreto.

pesquero debía reporta al fundo Botriano, como consecuencia del establecimiento de un negocio similar en el fundo vecino, y no para asegurar la tranquilidad ("Ruhe") del vendedor.

${ }^{7}$ La doctrina parece pronunciarse unánimemente en este sentido: WACKE, Andreas, cit. (n. 5), p. 213; HallebeEK, Jan, cit. (n. 1), p. 41; DajCZAK, Wojciech, L'uso della bona fides nei giuristi romani classici per la valutazione del valore vincolante degli accordi contrattuali, en RIDA., 44 (1997), pp. 81 ss. [http://www2.ulg.ac.be/vinitor/rida/1997/dajczak2.pdf]; FrANCIOSI, Gennaro, cit. (n. 2), p. 102; Purpura, Gianfranco, cit. (n. 2), p. 2.164; Mohino ManriQue, Ana, cit. (n. 2), p. 252.

${ }^{8}$ Sobre el posicionamiento de la doctrina, véase, más arriba, 2. 


\section{CONSTITUCIÓN DE SERVIDUMBRES EN LAS PROVINCIAS ROMANAS}

Como ya hemos advertido, el fragmento de Ulpiano habla de "personae possidentium", lo que nos informa de la segura naturaleza provincial de los fundos Botriano y Geroniano.

Por otra parte, el fragmento estudiado pertenece a los libri opinionum de Ulpiano. Como subraya Hallebeek ${ }^{9}$, generalmente, los libri opinionum solían servir a modo de manual para los gobernadores de las provincias, hecho que permitiría presumir que los fundos a los que el texto se refiere son provinciales. No sería de extrañar que Ulpiano, merced a su dilatada experiencia como funcionario en la cancillería imperial ${ }^{10}$, hubiera podido redactar una obra, que los gobernadores de las provincias utilizaran como guía en el enjuiciamiento de los casos de los que debieran conocer; especialmente si se tiene en cuenta que, como expresa Santalucia $^{11}$, a raíz de su experiencia en la cancillería imperial, este jurista habría tenido múltiples ocasiones para examinar los principios y reglas del derecho romano, desde la óptica de la compleja realidad provincial.

En lo que se refiere a la ubicación geográfica de los fundos Botriano y Geroniano, Franciosi ${ }^{12}$ los sitúa en Sicilia, partiendo de su denominación, especialmente del fundus Geronianus, y por la importancia, en época romana, de la pesca del atún en la isla.

Por su parte, Hallebeek ${ }^{13}$, cuya hipótesis parece gozar de mayor aceptación ${ }^{14}$, asocia el nombre del fundus Botrianus con la ciudad de Botria, situada en las costas del norte de África, próxima a Cartago y Hadrumento, y en territorio de la actual ciudad de Acholla, en Túnez ${ }^{15}$.

Partiendo, así pues, de que los fundos Botriano y Geroniano son predios

${ }^{9}$ Hallebeek, Jan, cit. (n. 1), p. 41.

${ }^{10}$ Fue miembro del consilium de Papiniano y secretario de la cancillería a libellis bajo el mandato de Septimio Severo (hasta el 209); bajo los gobiernos de Heliogábalo (218-222) y de Alejandro Severo, pudo desempeñar el cargo de praefectus annonae, hasta que fue ascendido a praefectus pretorii y parens (finales del año 222). Véanse: KunKEL, Wolfgang, Die römischen Juristen: Herkunft und soziale Stellung (reed. Köln, 2001), pp. 245 ss.; KNÜTEL, Rolf, voz "Ulpianus, Domitius", en Juristen. Ein biographisches Lexikon von der Antike bis zum 20. Jh. (Munich, 2001), p. 640 y 641; Honoré, Anthony, voz "Domicio Ulpiano", en Juristas universales (Madrid-Barcelona, 2004), I: Juristas antiguos, p. 208 a 211.

${ }^{11}$ Santalucia, Bernardo, cit. (n. 1), p. 208.

${ }^{12}$ Franciosi, Gennaro, cit. (n. 2), p. 102.

${ }^{13}$ Hallebeek, Jan, cit. (n. 1), p. 41, n. 11. Referencias a la pesca de atún en el norte de África y en época romana pueden hallarse en Plinio o Estrabón, que hablan de la pesca en Leptis, Syrtis Minor o en la isla de Meninx, así como en sus alrededores.

${ }^{14}$ Así, por ejemplo, DAJCZAK, Wojciech, cit. (n. 7), p. 81, ni tan sólo menciona la teoría de Franciosi. Purpura, Gianfranco, cit. (n. 3), p. 2165 y n. 8; Mohino ManriQue, Ana, cit. (n. 2), p. 252.

${ }^{15}$ En esta ciudad, se encuentra la villa de Asinius Rufinus, senador y cónsul en el año 184, bajo el imperio de Cómodo, cuyos mosaicos con motivos marinos dan fe de lo provechoso que el negocio del atún y de la pesca en general debía resultar en dichas tierras. Véanse: PuRPuRA, Gianfranco, cit. (n. 2), p. 2.165; GoZLAN, Suzanne, Les mosä̈ques de la maison d'Asinius Rufinus à Acholla (Tunisie), en las actas de Mosä̈que Gréco-romaine (Bath, 1994), V, p. 161 a 172. 
provinciales y en cuanto a la posibilidad de que se constituyera una servidumbre negativa de no pescar atún, se debe descartar que la constitución tuviera lugar de acuerdo con el ius civile, a través de mancipatio o de in iure cessio, al no ser posible su realización sobre suelo provincial (Gai. 2,14a, 27 ó 31).

Como sabemos a través de Gai. 2,31, en las provincias las servidumbres se constituían pactionibus et stipulationibus, es decir, a través de acuerdos relativos a la servidumbre, seguidos de una stipulatio poenae por la que se prometía que no se se obstaculizaría el ejercicio del mencionado derecho ${ }^{16}$.

Las referencias en el texto a la lex venditionis en conjunción con la presencia de una stipulatio han de interpretarse, como bien señala Franciosi ${ }^{17}$, como un

${ }^{16}$ Véase el claro ejemplo que nos proporciona Theoph. ad Inst. 2,3,4. A propósito de la constitución de servidumbres pactionibus et stipulationibus, véanse entre otros: PEROZzI, Silvio, I modi pretorii d'acquisto delle servitù, en Rivista italiana per le scienze giuridiche, 23 (1897), p. 3 ss. [= Scritti giuridici, II (Milano, 1948), II, pp. 199 ss.]; KRÜGER, Hugo, Die prätorische Servitut (Münster, 1911); FrEZZA, Paolo, Appunti esegetici in tema di modi pretori di costituzione di usufrutto e delle servitú prediali, en Studi economico-giuridici dell'Università di Cagliari, 22 (1934), p. 84 ss.; MAsCHI, Carlo Alberto, Contributi allo studio delle servitù pretorie, BIDR, 41 (1939), pp. 274 ss.; SolazzI, Siro, Requisiti e modi di costituzione delle servitù prediali (Napoli, 1947); El mismo, Specie ed estinzione delle servitù prediali (Napoli, 1948); El MISMO, La tutela e il possesso delle servitù prediali (Napoli, 1949); EL MISMO, Stipulazioni di servitù prediali, en Iura, 5 (1954), pp. 126-150; BIONDI, Biondo, Le servitù prediali nel diritto romano (Milano, 1969), pp. 248 ss.; Grosso, Giuseppe, Le servitù prediali nel diritto romano (Turín, 1969), pp. 192 ss.; Provera, Giuseppe, cit. (n. 1), pp. 27 ss. La Rosa, Franca, Pactionibus et stipulationibus, Labeo, 40 (1994) 1, pp. 27 ss.; BAsIle, Raffaele, Pactionibus et stipulationibus id efficere, en " $F i$ des, humanitas, ius". Studii in onore di Luigi Labruna (Napoli, 2007), I, pp. 335 ss.; ZuCCOTTI, Ferdinando, Sulla tutela processuale delle servitù cosidette pretorie, en Atti del Convegno "Processo civile e processo penale nell'esperienza giuridica del mondo antico", Siena, Certosa di Pontignano, 13-15 decembre 2001, pp. 182-183 (http://www.ledonline.it/rivistadirittoromano/allegati/ attipontignanozuccotti.pdf); MÖLLER, Cosima, Entwicklungs-geschichte, Funktion und Struktur der grundstückvermittelten Privatrechtsverhältnisse im römischen Recht. Mit einem Ausblik auf die Rezeptionsgeschichte und das BGB (Göttingen, 2010), pp. 330 ss.; FinkenaUer, Thomas, cit. (n. 1), pp. 331 ss. Este tipo de constitución de servidumbres tendría lugar, como decíamos, a través de acuerdos libres de forma relativos a la servidumbre que las partes quieren constituir y de los cuales derivaría la eficacia jurídico-real del acto, acompañados de stipulationes de ejercicio-Cfr. D. 8,1,20 (Iav., 5 ex post. Lab.); D. 19,1,3,2 (Pomp., 9 Sab.)- que, usualmente, incorporan una cláusula penal para el caso de incumplimiento. Estas estipulaciones penales, que aparecen en los textos bajo la estructura de una Doppelstipulation (ad ex. D. 45,1,85, 3 Paul., 75 ad ed.), debieron recogerse, generalmente, por escrito y solían contener la mentio heredis, para asegurar su transmisibilidad a los herederos de las partes $-v$. gr. Paul. D. 10,2,25,12 (23 ed.); D. 10,2,44,5 (6 Sab.); D. 45,1,2,5 y 6 (12 Sab.); D. 45,1,83pr. (72 ed.); D. 45,1,85,3 (75 ed.); D. 45,1,92 (18 Plaut.); Scaev. D. 45,1,131pr. (13 quaest.) y D. 45,1,133 (ibid.). La costumbre de acompañar los acuerdos constitutivos de la servidumbre de stipulationes poenae explicaría que los juristas romanos expresaran que la servidumbre se habría constituido pactionibus et stipulationibus, como afirma Gai. 2,31.

${ }^{17}$ Franciosi, Gennaro, cit. (n. 2), p. 102: "La menzione della stipulatio accanto alla lex venditionis non deve meravigliare, in quanto il giurista, allargando il discorso, comprende l'ipotesi della costituzione aggiuntiva della servitù mediante pactio et stipulatio". También, TALAMANCA, Mario, cit. (n. 2), pp. 909 ss. Sigue la opinión de Talamanca, pero se plantea la posibilidad de la eficacia real de las pactiones et stipulationes en provincias, Gai. 2,31; FIORENTINI, Mario, cit. (n. 2) p. 424 n. 85. 
caso de constitución de servidumbre pactionibus et stipulationibus. Por tanto, no tiene sentido entender que el texto está interpolado y defender que, originariamente, Ulpiano habría recogido un caso de deductio servitutis ${ }^{18}$. Dado que el suelo provincial no es susceptible de mancipatio, el jurista nunca pudo hablar de una lex mancipio dicta ${ }^{19}$, de ahí que exprese que se trata de una lex venditionis o stipulationis.

Cabe recordar que la sola compraventa no sería capaz de constituir una servidumbre, pues, en el Derecho romano clásico, la compraventa no se concibe como un contrato generador de derechos reales, sino consensual y meramente obligacional; de modo que, si la compraventa por sí misma no es suficiente para transmitir la propiedad sobre la cosa comprada, por lógica tampoco permitirá la constitución de una servidumbre.

Obviamente, en época clásica, el titular de dos predios que decide enajenar uno de ellos puede disponer, en la compraventa, a favor del predio que conserva o del que enajena, la constitución de una servidumbre. No obstante y según el ius civile, tal servidumbre no surge de la propia compraventa, sino de la realización de un negocio formal como sería la mancipatio. En la celebración de la mancipatio, el mancipio dans debe reservarse de forma expresa la servidumbre -ex D. 8,4,10 (Ulp., 10 Sab.)- pronunciando determinadas cláusulas de estilo: las leges mancipio dictae. Esta modalidad de constitución viene indicada, en los textos de la jurisprudencia clásica, con el uso de los términos excipere ${ }^{20}$, en el caso de constituir una servidumbre a cargo del fundo enajenado, o recipere ${ }^{21}$, en el caso de que la servidumbre se constituya a su favor. La utilización de estos verba se remontaría a época republicana, desde el siglo II a. C. ${ }^{22}$

En ámbito provincial, la reserva de servidumbre realizada en la compraventa

${ }^{18}$ En este sentido, Perozzi, Silvio, Scritti giuridici: Servitù e obbligazioni (Milano, 1948), II, pp. 204 ss. Para Solazzi, los compiladores habrían adecuado este fragmento a la nueva realidad de la compraventa como modo de constitución de las servidumbres, la lex venditionis habría dado lugar a la servidumbre y la referencia final a la stipulatio sería una interpolación o glosa. SolAzzi, Siro, Requisiti e modi di costituzione delle servitù prediali (Napoli, 1947), pp. 97-98.

${ }^{19}$ KaSER, Max, cit. (n. 2), pp. 93 ss.; AlBAnESE, Bernardo, Gli atti negoziali nel diritto privato romano (Palermo, 1982), p. 45 n. 59. HallebeeK, Jan, cit. (n. 1), p. 41; Randazzo, Salvo, Leges mancipii. Contributo allo studio dei limiti di rilevanza dell'accordo negli atti formali di alienazione (Milano, 1998), p. 103 n. 58. Cabe destacar que éste es el único texto del Digesto que recoge la expresión "lex privata”, expresión que es interpretada como una referencia poco técnica a legem dicer. Véase: KASER, Max, cit. (n. 2), p. 94.

${ }^{20}$ Cfr. D. 8,3,30 (Paul., 4 ep. Alf. dig.) o D. 8,4,7 pr. (Paul., 5 Sab.).

${ }^{21}$ Cfr. D. 8,4,6,3a (Ulp., 28 Sab.) o D. 8,4,10 (Ulp. ,10 Sab.)

${ }^{22} \mathrm{La}$ elaboración jurisprudencial de detrahereldeducere usufructum sería posterior, de finales de la época republicana e inicios de la época imperial. Tendría lugar a través de una modificación de la estructura de la declaración principal relativa a la propiedad de un inmueble, realizada por el vendedor o comprador. Esta modificación confiere a la declaración un efecto más restringido del que tendría normalmente. Esta forma de constitución no sería aplicable en el caso de la mancipatio, al representar una parte del contenido de la propiedad, lo que no era posible en el caso de las servidumbres prediales. Véanse: LA Rosa, Franca, "Deducere usum fructum, excipere servitutem”, en Studi in onore di Cesare Sanfilippo (Milano, 1987), VII, pp. 321 ss.; SANTOS Rojo, Cristina, La reserva de servidumbre (Valencia, 2001), pp. 117 ss.; Mohino ManriQue, Ana, cit. (n. 2), pp. 222 ss. 
no tendría una eficacia diferente a lo que sucedería sobre suelo itálico y, por tanto, no sería suficiente para la constitución de la servidumbre. Pues no parece que pueda concebirse una compraventa con una eficacia diferente, según se celebre ésta en Roma o en las provincias. Ello no impide pensar que la constitución pactionibus et stipulationibus de las servidumbres no pudiera tener lugar con motivo de la compraventa de un fundo, como pudiera haberse producido en la venta del fundo Geroniano. En tal sentido debe entenderse el siguiente fragmento de Gayo, conservado en D. 8,4,3 (Gai, 7 ed. prov.): "Duorum praediorum dominus si alterum ea lege tibi dederit, tu id praedium quod datur serviat ei quod ipse retinet, vel contra, iure imposita servitus intellegitur".

Si el dueño de dos predios hubiese dado uno incluyendo la cláusula de que el predio que se da preste servidumbre al que se retiene, o al revés, se entiende impuesta la servidumbre con arreglo a Derecho ${ }^{23}$.

Tratándose de un comentario al edicto provincial y, por tanto, partiendo de que Gayo se ocuparía aquí de fundos provinciales, la primera cuestión que nos resulta un tanto extraña sería el uso de "dominus" para referirse a la relación que tiene el individuo con los predios. Normalmente, dominus se asocia con la idea de dominium ex iure Quiritium. Sobre el suelo provincial, los particulares no disponían de este tipo de propiedad, reservada al suelo itálico, sino de una plenísima posesión ${ }^{24}$ que el mismo Gayo denomina possessio vel usufructus (Gai. 2,7). Es posible que el texto sufriera las modificaciones oportunas por parte de los compiladores, antes de ser recogido en el libro 8 del Digesto ${ }^{25}$, aunque el uso de dominus bien podría deberse al propio Gayo, hecho que subrayaría, en cierto modo, la plenísima posesión de que disfrutaban los particulares sobre el suelo provincial, que justificaría que se refiera a ellos como domini.

La referencia a una lex en conjunción con la datio también genera no pocas dudas. Para Biondi ${ }^{26}$, el texto de Gayo seguramente debió referirse, en sus orígenes, a mancipio dare, tratándose, por tanto, de un caso de mancipatio o de in iure cessio, a través de las cuales era posible la transmisión de la propiedad del fundo (dare), a la vez que se constituía la servidumbre mediante una lex mancipio dicta. Grosso ${ }^{27}$ también entiende que el texto está interpolado y que, en su versión clásica, Gayo se ocupaba de una reserva de servidumbre en el marco de una mancipatio o in iure cessio. En esta misma línea de pensamiento se encontraría Albanese ${ }^{28}$. Solazzi ${ }^{29}$ partía de la posibilidad de que el texto contuviera una comparación entre el régimen propio del suelo itálico y el de las provincias, pero los compiladores habrían eliminado dicha comparación por no tener sentido en época justinianea, de ahí

${ }^{23}$ BeHrends, Okko y otros, cit. (n. 3), p. 699.

${ }^{24}$ Cfr. Theoph. ad Inst. 2,1,40.

${ }^{25}$ Antes hemos podido comprobar cómo Ulpiano, jurista posterior a Gayo, en D. 8,4,13pr. (6 opin.), habla de possessores al referirse a fundos provinciales.

${ }^{26}$ BIONDI, Biondo, cit. (n. 16), p. 223.

${ }^{27}$ Grosso, Giuseppe, cit. (n. 16), p. 188 n. 2.

${ }^{28}$ Albanese, Bernardo, cit. (n. 19), p. 47,n. 62.

${ }^{29}$ SolazZI, Siro, cit. (n. 18), pp. 89 ss. 
que la parte final del fragmento, "iure imposita servitus intellegitur", en realidad, se estaría refiriendo a la reserva de servidumbre en el ius civile.

Sin embargo, creemos, al igual que Randazzo ${ }^{30}$, que esta referencia final no parece que se haga en relación con la mancipatio o la in iure cessio, pues no sería necesaria tal especificación, que podría considerarse una redundancia, ya que es obvio que la mancipatio o la in iure cessio dan lugar a que la servidumbre se constituya con arreglo a derecho. En cambio, tal expresión o puntualización de Gayo sí resulta más acorde con una posible constitución de la servidumbre en provincias conforme a lo que Randazzo denomina "pactio servitutis", en consonancia con lo que el mismo jurista expresa en Gai. 2,31; es decir, la constitución pactionibus et stipulationibus. Gayo estaría, por tanto, subrayando que, en el caso de los fundos provinciales, se constituía la servidumbre conforme a derecho, es decir, conforme al modo de constitución vigente en las provincias, las pactiones et stipulationes.

\section{LA PROHIBICIÓN DE PESCAR ATÚN EN D. 8,4,13 PR.: ¿UNA SERVIDUMBRE CONSTITUIDA "PACTIONIBUS ET STIPULATIONIBUS"?}

1. La prohibición de pescar atún, en el fragmento que nos ocupa, se establece en el momento de realizarse la compraventa y, de acuerdo con lo que expresa el fragmento, puede materializarse jurídicamente incorporándose a este contrato como un pactum adiectum (lex venditionis), acompañado de una stipulatio de ejercicio (lex stipulationis). De este modo, se explicaría la referencia a la lex venditionis vel stipulationis que recoge el texto, utilizando una conjunción disyuntiva. Para algunos autores ${ }^{31}$, la referencia a la lex stipulationis se correspondería con una interpolación, los compiladores habrían incluido la mención a la stipulatio debido a que, en época justinianea, el modo general de constitución de las servidumbres son las pactiones et stipulationes. Se aduce, además, que el caso del que se ocupa Ulpiano se ceñiría al estudio de la compraventa y de las cláusulas añadidas a este contrato, pero no a la stipulatio, que rara vez solía cumplir con este tipo de funciones, al utilizar las partes preferentemente los pacta adiecta para ajustar el contrato a su conveniencia.

\footnotetext{
${ }^{30}$ Randazzo, Salvo, cit. (n. 18), pp. 103 ss.; y en "Servitus iure imposita". Destinazione del padre di famiglia e costituzione "ipso iure" della servitù, en RDR., 2 (2002), pp. 289 ss. [disponible en http://www.ledonline.it/rivistadirittoromano/allegati/dirittoromano02randazzo.pdf]. No podemos estar más de acuerdo con este autor cuando expresa que, para entender el significado de "iure imposita" en el fragmento, es necesario dar por superados no pocos condicionantes dogmáticos. Para Gayo, la constitución de las servidumbres pactionibus et stipulationibus se situaría al mismo nivel que la constitución conforme a los modos del ius civile, se trataría por tanto de diferentes modos de constitución, pero todos ellos serían jurídicamente fundados y vinculantes. De otro manera, esta mención a "iure" no podría entenderse, más que como una referencia poco técnica o casual o incluso como fruto de un añadido compilatorio. El autor sigue a La Rosa y defiende que el origen de las pactiones et stipulationes se encontraría en los fundos itálicos, desde donde pasarían a los fundos provinciales.

${ }^{31}$ Perozzi, Silvio, cit. (n. 18), p. 205 y n. 1; Solazzi, Siro, cit. (n. 18), p. 27. En contra de este último, Biondi, Biondo, cit. (n. 16), p. 194; SANTAlUCia, Bernardo, cit. (n. 1), p. 254 n. 20; Mohino Manrique, Ana, cit. (n. 7), pp. 254-255.
} 
Siguiendo a Wacke ${ }^{32}$, nos parece que la compraventa, en este supuesto, no sólo tiene como objeto el fundo Geroniano, sino también el negocio de pesca existente en éste; lo que sin duda alguna debió de influir en la decisión de comprar el fundo así como en el precio a pagar por él. El fundo Geroniano no es un simple fundo de recreo, sino que en él existe una explotación pesquera y ésta es la que interesa al comprador. Debemos tener en cuenta, asimismo, que la prohibición que se establece en la venta no es una prohibición genérica de pescar, pues esto hubiera impedido la explotación pesquera del fundo y seguramente hubiera disuadido al comprador en su adquisición. La prohibición afecta únicamente a un pescado en concreto: el atún. El comprador podría dedicarse a la pesca y elaboración posterior de cualquier otro tipo de pescado, moluscos o marisco, sin problema alguno, pero nunca a la pesca de atún. Esta prohibición, por tanto, no se impone por un mero deseo de paz o tranquilidad del poseedor del fundo Botriano, sino para asegurar que el negocio del fundo vecino no le hace la competencia o, incluso, para asegurarse el monopolio en la comercialización del atún en la población en la que estuvieran situados los fundos Geroniano y Botriano ${ }^{33}$.

Posiblemente, el vendedor intentó imponer la prohibición de pescar atún en el fundo vendido, a través de la constitución de una servidumbre y de acuerdo con la estructura de las pactiones et stipulationes, ya que así es como se constituyen las servidumbres en provincias (Gai. 2,31). Aunque lo hizo de un manera un tanto torpe, pues como señala Ulpiano, no es posible constituir una servidumbre sobre el mar. De ahí que no podamos desdeñar tan deprisa la referencia final a la lex stipulationis. Incluso con toda seguridad es posible que se hubiera tratado de una stipulatio poenae, pues debido al elevado interés económico en juego, el vendedor podría haber fijado una suculenta pena en previsión de un posible incumplimiento de la prohibición.

Es más, basta con observar el motivo en el que el jurista basa su decisión para no considerar que exista una servidumbre en este caso. Este motivo no se refiere tanto a la existencia o validez del acto constitutivo de la servidumbre -caso que esto, la constitución de una servidumbre, fuera lo que pretendieran las partes realmente en el momento de realizar la compraventa, como nos parece que debió ser-, como al hecho de que no es posible la constitución de la servidumbre sobre

${ }^{32}$ WaCKe, Andreas, cit. (n. 6), p. 213.

${ }^{33}$ En el caso de la pesca del atún en el Estrecho de Gibraltar, Gozalbes ha destacado que las investigaciones arqueológicas muestran que el mayor apogeo de la pesca de atún debió producirse durante el s. II d. C., mientras que en el siglo III d. C. se inicia una fuerte disminución de la pesca y de la producción de salazones, hasta el punto de poder hablar de decadencia de esta actividad. En el siglo IV d. C., la producción ya era muy escasa, pese a que algunas factorías de salazón continuaban con su actividad comercial. Es posible que esta progresiva decadencia de la pesca del atún, que se vivía en el Estrecho, también hubiera afectado al resto de zonas en las que tradicionalmente se pescaba atún, como consecuencia de una disminución de las poblaciones de esta especie. Este hecho podría justificar, con más razón, el interés del vendedor por evitar la posible competencia en el fundo vecino. Véase: Gozalbes Cravioto, Enrique, La pesca del atún en la antigüedad, en Aljaranda. Revista de Estudios Tarifeños. Ayuntamiento de Tarifa, 34 (1999), p. 3 [http://www.tarifaweb.com/aljaranda/num34/art5.htm]. 
el mar, lo que las partes habrían indicado al intentar constituir la servidumbre -téngase en cuenta, que es muy posible que se documentara la compraventa.

No es posible constituir una servidumbre sobre el mar, ya sea sobre los predios itálicos o los provinciales, ya sea en virtud del ius civile o del ius praetorium, pues el mar se concibe como una cosa que pertenece a todo el mundo ${ }^{34}$ (res communis omnium) y que, por tanto, puede ser usada por todos, como dice D. 1,8,2,1 (Marc., 3 inst.): "Et quidem naturali iure omnium communia sunt illa: aer, aqua profluens, et mare, et per hoc litora maris".

No sería posible limitar o prohibir el uso de las cosas que, por Derecho natural, se encuentran a disposición de todos los hombres. En este sentido, la prohibición de pescar en el mar se consideraría una lesión constitutiva de iniuria y permitiría ejercer la actio iniuriarum conforme a Pomponio y a Ulpiano en D. 47,10,13,7 (Ulp., 57 ed.): "Si quis me prohibeat in mari piscari vel everriculum (quod Graece sagyny dicitur) ducere, an iniuriarum iudicio possim eum convenire? sunt qui putent iniuriarum me posse agere: et ita Pomponius et plerique esse huic similem eum, qui in publicum lavare vel in cavea publica sedere vel in quo alio loco agere sedere conversari non patiatur, aut si quis re mea uti me non permittat: nam et hic iniuriarum conveniri potest. conductori autem veteres interdictum dederunt, si forte publice hoc conduxit: nam vis ei prohibenda est, quo minus conductione sua fruatur. si quem tamen ante aedes meas vel ante praetorium meum piscari prohibeam, quid dicendum est? me iniuriarum iudicio teneri an non? et quidem mare commune omnium est et litora, sicuti aer, et est saepissime rescriptum non posse quem piscari prohiberi: sed nec aucupari, nisi quod ingredi quis agrum alienum prohiberi potest. usurpatum tamen et hoc est, tametsi nullo iure, ut quis prohiberi possit ante aedes meas vel praetorium meum piscari: quare si quis prohibeatur, adhuc iniuriarum agi potest. in lacu tamen, qui mei dominii est, utique piscari aliquem prohibere possum".

La servidumbre podría haberse constituido, en principio, si en vez de referirse al mar, la prohibición se hubiera referido al fundo Geroniano. En la pesca del atún -nos referiremos a ella a continuación-, también jugaría un papel capital el fundo, pues, como veremos, algunas de las actividades relacionadas con la pesca tendrían lugar en él, como sería el avistamiento de los bancos de atunes desde torres de vigilancia situadas en la costa o, en algunos casos, en tierra podría darse muerte a los atunes. También se prepararía en tierra el pescado para su salazón. De este modo, sería posible que la prohibición se hubiera podido referir a la realización de dichas actividades sobre el fundo, en lugar de la pesca sobre el mar, dando lugar a una servidumbre consistente en un non facere.

2. Resulta conocida la importancia de la pesca del atún y de los establecimientos para la preparación y salazón de este pescado o la producción de la salsa garum en las costas de Sicilia, así como las del norte de África, la costa mediterránea de la península ibérica, principalmente del Estrecho, y la parte meridional de la costa

\footnotetext{
${ }^{34}$ Sobre el régimen jurídico del mar, recientemente: GARCía QuINTAS, Ma de las Mercedes, El mar desde la perspectiva jurisprudencial romana, en $R G D R$., 15 (2010), véanse especialmente las pp. 4 ss. Concretamente, en la p. 9, la autora hace hincapié en la imposibilidad de constituir una servidumbre sobre el mar y cita expresamente el texto de Ulpiano de D. 8,4,13 pr.
} 
de la península itálica ${ }^{35}$. La importancia del atún en la antigüedad no radicaba únicamente en los grandes beneficios económicos que generaba su comercialización ${ }^{36}$, sino también en las propiedades medicinales de las que goza este pescado, que lo hacen especialmente apreciado en la dieta romana ${ }^{37}$.

Debe observarse también, que la pesca del atún sólo puede producirse en determinadas épocas del año, esto es a finales de primavera (el mayor tránsito de este pescado se produce durante la denominada "luna de mayo"), cuando tiene lugar su migración, desde el Atlántico hacia el Mediterráneo y viceversa, para el desove. Estrabón (3,2,7 y 8) describía a los atunes que se pescaban en la costa del Estrecho, como especímenes espectaculares en cuanto a tamaño, orondos y grasos, ya que se alimentaban de las bellotas, que crecían en supuestas encinas a nivel del mar; de ahí que también fueran conocidos con el nombre de "cerdos de mar".

El atún nada en grandes bancos, bordeando las zonas costeras, lo que permite su captura, ya desde época romana, a través de técnicas similares a las modernas almadrabas o atunaras (tonnara en Sicilia). Las almadrabas (denominación que proviene del árabe y que significa lugar donde se golpea o lucha) se caracterizan por ser un dispositivo laberíntico de mallas mediante las que se acorrala y encierra a los atunes y cuyas redes están fijadas al fondo del mar del litoral en distintas formas (de vista o tiro, de monte y leva y de buche) y con una base en tierra.

Recientemente, Purpura ${ }^{38}$ ha destacado que, en época medieval y moderna, se habría perdido el uso de las técnicas de captura del atún del mundo antiguo, según las cuales, los atunes no morirían en alta mar, en las denominadas cámaras de la muerte, como ocurre hoy en día, sino en las riberas del litoral mediterráneo. En la antigüedad, se conocieron, como instalaciones de pesca fija, únicamente los

${ }^{35}$ Purpura, Gianfranco, cit. (n. 2), p. 2.164 n. 4.

${ }^{36}$ La importancia del atún como elemento básico de la economía en algunas ciudades puede apreciarse en la acuñación de monedas, en las que aparecen referencias a este animal. Sería el caso de ciudades hispanas como Baelo Claudia, Asido Caesarina, Gades o Iulia Traducta. Concretamente, en Baelo Claudia está documentada la existencia de cuatro fábricas de salazones y se calcula que, en época de pesca, la producción mensual podía alcanzar los mil metros cúbicos de pescado. Véanse: Liaño Rivera, M. La pesca del atún. Salir por la vía de Tarifa, en Aljaranda. Revista de estudios tarifeños. Ayuntamiento de Tarifa, 26, (1997), p. 1 [http://www.tarifaweb. com/aljaranda/num26/art1.htm]; Gozalbes Cravioto, Enrique, cit. (n. 32), n. 1. Sobre la importancia de la pesca en la economía romana, resulta muy interesante la lectura de BLÁZQUEZ Martínez, José Ma, La pesca en la antigüedad y sus factores económicos, en Antigua. Historia y arqueología de las civilizaciones. Portal temático de la Biblioteca Virtual Miguel de Cervantes, pp. 7 ss. [http://www.cervantesvirtual.com/Portal/Antigua/index.shtml].

${ }^{37}$ Así, por ejemplo, autores como Estrabón, Plinio, Galeno o Marco Manilio se hacen eco de los beneficios para la salud del uso del atún en la cocina. También resulta conocido el uso del garum en la medicina y en la cosmética. Véase: Franciosi, Gennaro, cit. (n. 2)., p. 103.

${ }^{38}$ Purpura, Gianfranco, cit. (n. 2), p. 2167 ss. En el mismo sentido, García Vargas, Enrique, Pesca, saly salazones, en Treballs del Museu Arqueològic d'Eivissa i Formentera, 47 (2001), número que recoge las actas del congreso De la mar y de la tierra: producciones y productos fenicio-púnicos. XV Jornadas de Arqueología fenicio-púnica (Eivissa, 2000), pp. 9 ss., ha expresado, para el caso de las costas andaluzas, que la introducción de las denominadas almadrabas de buche o sicilianas, que incluyen una "cámara de la muerte" (la tonnara siciliana), no tendría lugar hasta el siglo XIX y muy a pesar de la decidida oposición de los pescadores. 
denominados corrales (laberintos de caña en aguas bajas), los recintos de redes y los recintos de presa de los bancos migratorios de peces.

La técnica de pesca utilizada en la Roma clásica, por regla general y según Purpura $^{39}$, consistía en establecer una trampa de redes, normalmente de carácter fijo, cercana a la costa, en la que se capturaba el pescado. La llegada de bancos de atunes se controlaría desde torres de vigilancia o atalayas situadas en tierra y, una vez los peces quedaran atrapados en las redes, se conducirían hacia el fondo de la ensenada costera, a través de redes de arrastre y con la ayuda de barcas. La estrechez de las redes daba lugar a la muerte de los atunes por asfixia o incluso como consecuencia de los golpes de sus colas. Para procurar su muerte, los pescadores también solían valerse de arpones o bastones con los que golpeaban a los ejemplares capturados.

Este método sería muy similar al descrito por Claudio Eliano ${ }^{40}$ en su de natura animalium, en relación con la pesca en el mar Negro. Este autor sugiere, además, que el método debía ser muy parecido al que se empleaba en Sicilia. Según Claudio Eliano, que habría vivido en la misma época que Ulpiano, los pescadores utilizaban barcas, redes y establecían una atalaya que se ubicaba en el litoral. El vigía en la atalaya debía dar aviso a las barcas de la proximidad de los bancos de atunes. Cada barca tenía, a cada costado, seis remeros jóvenes y buenos conocedores del oficio. Las redes eran de grandes dimensiones y lastradas con plomo y los peces entraban en ellas en tropel.

El poeta Oppiano de Corycus ${ }^{41}$, poeta griego del siglo II d. C., algo anterior, por tanto, a Claudio Eliano, dedica un poema sobre la pesca al emperador Marco Aurelio y a su hijo Cómodo: Halieutica. En él también describe el método de pesca del atún en las costas hispanas, sobre todo en el Estrecho, subrayando que era el mismo método que se utilizaba en la costa de la península ibérica, en la Galia y en Sicilia. También se refiere al trabajo del experto vigía, que era capaz de calcular el tamaño y cantidad de atunes desde la atalaya. Después del avistamiento, se preparaban las redes, que el poeta compara con una especie de ciudad entre las olas, dentro de las cuales entraban los atunes en hileras y con gran rapidez, hasta completar el número de atunes que la red fuera capaz de apresar. En algunos casos, se empleaba como cebo un pescado denominado coracinos (pez cuervo) ${ }^{42}$.

Atendiendo al método empleado para la pesca del atún, Fiorentini ${ }^{43}$ sabiamente considera que la finalidad última del vendedor del fundo Geroniano, al intentar constituir una servidumbre, pudo ser evitar que se implantara una almadraba en

${ }^{39}$ Este autor defiende que esta técnica de pesca sería la que permitiría entender el fragmento de Ulpiano y apreciar la existencia de una servidumbre negativa. PURPURA, Gianfranco, cit. (n. 2), p. 2167: "La soluzione del dubbio giuridico e testuale si trova, a mio avviso, nel fatto che nell'età medioevale e moderna si era ormai perduta la conoscenza di una tecnica di cattura del tonno tipica dell'età classica che implicava l'uccisione dei pesci, non in alto mare in una "camera della morte" come avviene oggi, ma proprio sulla riva del fondo litoraneo".

${ }^{40}$ De natura animalium, 15,5 y 6.

${ }^{41}$ Halieutica, 3, 31 ss.

${ }^{42}$ Gozalbes Cravioto, Enrique, cit. (n. 32), p. 2.

${ }^{43}$ Fiorentini, Mario, Sulla rilevanza economica e giuridica delle ville marittime durante la Reppublica e l'Impero, en Index, 24 (1996), p. 169. 
el fundo vecino, con las consecuencias que ello comportaba en relación a la instalación en tierra de torres de vigilancia, cámaras para la conservación y elaboración del pescado, las actividades de pesca a desarrollar frente el fundo vecino, etc.

3. Otros de los elementos a tener en cuenta, para determinar la posibilidad de constitución de una servidumbre sobre el fundo Geroniano, sería si se verificaría, en este caso, el requisito de la utilitas. Una característica de toda servidumbre es la de reportar al fundo dominante una determinada ventaja o utilidad objetiva y no un simple interés personal u ocasional de su propietario. La servidumbre que se pretendía imponer sobre el fundo Geroniano buscaría evitar que el comprador se dedicara a la misma actividad que el vendedor, con el consiguiente perjuicio económico para éste último, si bien el texto señala que la prohibición se establece, no en favor del vendedor, sino del fundo Botriano - si se entiende que "ne contra eum" se está refiriendo a dicho fundo y no al vendedor ${ }^{44}$. Esta prohibición, además, debió influir en la determinación del precio final del fundo. Para Wacke ${ }^{45}$, la prohibición de pescar atún bien podría ser el contenido de una servidumbre negativa. El problema sería determinar si, en el derecho romano clásico, se admitían o no las denominadas servidumbres industriales, es decir, una servidumbre cuya constitución se justifique por aportar una ventaja en relación con la industria desarrollada en el fundo dominante.

En este sentido, en época clásica, no parece aceptarse la constitución de servidumbres que benefician al negocio del titular del predio dominante y no al propio predio, como parece extraerse de la opinión de Paulo, contemporáneo de Ulpiano, en D. 8,3,6 pr. (Paul., 15 Plaut.), en el que se considera usufructo y no servidumbre el tener alfarerías en el fundo vecino para un negocio de venta de vasijas: "Veluti si figlinas haberet, in quibus ea vasa fierent, quibus fructus eius fundi exportarentur (sicut in quibusdam fit, ut amphoris vinum evehatur aut ut dolina fiant), vel tegulae vel ad villam aedificandam. Sed si, ut vasa venirent, figlinae exercerentur, usus fructus erit".

Sin embargo, como recuerda Grosso ${ }^{46}$ y dada la naturaleza casuística del derecho romano, a raíz de este texto no puede establecerse una generalización ${ }^{47}$, según

\footnotetext{
${ }^{44}$ Como interpreta Acursio, gl. contra eum: "Scilicet Botroianum, id est fontem eius, cum esset iuxta mare". Citamos a través de una edición del Corpus iuris civilis cum glossis (Lyon, 1627). En el mismo sentido, Hallebeek, Jan, cit. (n. 1), p. 46.

${ }^{45}$ WACKE, Andreas, cit. (n. 5), p. 214.

${ }^{46}$ Grosso, Giuseppe, cit. (n. 17), pp. 101 ss.

${ }^{47}$ Otros posibles argumentos para subrayar la inadmisibilidad de las servidumbres industriales tendrían que ver con la imposibilidad de constituir una servidumbre para el disfrute de un sujeto o por su mero capricho, de acuerdo con D. 8,1,8 pr. (Paul., 15 Plaut.); o que la utilitas que obtiene el fundo dominante no puede consistir en que este fundo tenga un mayor valor económico como consecuencia de la servidumbre. Sin embargo el aumento del valor del fundo dominante puede considerarse, en el caso de las servidumbres industriales, como un plus, que también se produce respecto de cualquier otro fundo que disfruta de una servidumbre. En cualquier caso, la cuestión determinante es que, a través de la servidumbre, el fundo dominante obtenga una utilidad en relación con la finalidad económico-social a la que se destina dicho predio, lo que no parece suceder en el anterior texto relativo a las alfarerías. Véanse: TALAMANCA, Mario, Istituzioni
} 
la cual, el derecho romano clásico no habría conocido la servidumbre industrial ${ }^{48}$, sino que se debería estar al caso concreto y determinar, así pues, en cada supuesto, si la utilidad la obtiene directamente el titular o bien el propio fundo.

Una servidumbre cuyo contenido sea la prohibición de la práctica de la pesca del atún en el fundo vecino no sólo implica una limitación a los derechos del titular del fundo gravado, sino que también estaría reportando una utilidad objetiva al fundo a favor del cual se constituye la servidumbre, pues sin duda alguna, posibilita la mejor explotación económica de este predio, destinado a la pesca y comercialización del atún ${ }^{49}$.

4. Otra de las cuestiones que se aducen, para argumentar que la prohibición de pesca en el fundo no podría ser el contenido de una servidumbre negativa, sería la de la tipicidad de las servidumbres. Una servidumbre cuyo contenido fuera la prohibición de practicar la pesca del atún se separaría del pretendido numerus clausus de servidumbres reconocidos por la jurisprudencia. No obstante, el derecho romano clásico no conoce un concepto unitario de servidumbre, sino que, en cada caso, la jurisprudencia se encarga de construir diferentes tipos a partir de unas características y requisitos comunes. En ámbito provincial, merced a la constitución pactionibus et stipulationibus de las servidumbres, las partes habrían gozado de mayor libertad si cabe, en cuanto a la configuración de la servidumbre que querían constituir. Como recuerda Franciosi ${ }^{50}$ una cosa sería la tipicidad y el numerus clausus de los iura in re aliena como categoría y otra el problema del presunto y rígido numerus clausus de los supuestos que pueden dar lugar a una servidumbre predial, en palabras de este mismo autor, "il numerus clausus è orientamento tendenziale, non un tabù inviolabile”.

5. De este modo, el vendedor del fundo Geroniano pudo llegar a constituir una servidumbre negativa, cuyo contenido sería la prohibición de ejercer la pesca del atún sobre el fundo Geroniano en perjuicio del Botriano, siempre y cuando no hubiera cometido el error de intentar constituirla sobre el mar. Esta constitución habría tenido lugar a través de pactiones et stipulationes, sobre todo teniendo en cuenta que éste era el modo de constitución propio de las provincias, como indica Gai. 2,31. Por tanto, nos encontraríamos ante un caso en el que sí se emplean las pactiones et stipulationes para constituir una servidumbre, si bien, el error de la mención del mar por parte del vendedor impide que la servidumbre pueda llegar a surgir.

de diritto romano (Milano, 1990), pp. 456-457; GIUFFrÈ, Vincenzo, L'emersione dei iura in re aliena ed il dogma del numero chiuso (Napoli, 1992), \$17, pp. 182 ss.

${ }^{48}$ En este sentido, Biondi, Biondo, cit. (n. 17), pp. 191 ss. Solazzi, Siro, cit. (n. 18), pp. 25 ss.

${ }^{49}$ Corbino adimite expresamente la existencia de un ejemplo de servidumbre industrial en este texto de Ulpiano, véase: Corbino, Alessandro, s.v. "Servitü", en ED. (Milano, 1990), XLII, p. 259 n. 234.

${ }^{50}$ FranCIOSI, Gennaro, cit. (n. 2), pp. 105 ss. Asimismo, sobre esta cuestión, véase: GiUfFrè, Vincenzo, cit. (n. 46), pp. 198-199. 
Este error del vendedor al formular la lex venditionis refiriéndose al mar, en vez de al fundo vendido, es lo que conduce a Ulpiano a decir que no puede entenderse que, en este caso, se hubiera constituido una servidumbre válidamente: "quamvis mari, quod natura omnibus patet, servitus imponi privata lege non potest”.

Pero aunque no pudo constituirse una servidumbre sobre el fundo Geroniano, Ulpiano considera que la prohibición introducida a través de una lex venditionis o la stipulatio, vincula igualmente, basando su opinión en la buena fe del contrato de compraventa.

Como subraya Mohino ${ }^{51}$, la decisión de Ulpiano de admitir la validez de esta cláusula prohibitoria podría plantearse desde el punto de vista de entender que esta cláusula tendría un carácter esencial en la compraventa, en el sentido de que, sin su presencia, seguramente aquella no habría tenido lugar. Hasta el punto de que, si la cláusula se entiende nula -al no haberse constituido correctamente la servidumbre-, esto podría determinar, a su vez, la nulidad del contrato. Para evitar esta solución extrema, Ulpiano recurre a la buena fe inherente en el contrato de compraventa y sostiene su validez ${ }^{52}$.

\section{Sujetos VINCULAdOS POR LA PROHIBICIÓN DE NO PESCAR ATÚN}

La duda en cuanto a quién queda vinculado a través de la cláusula surge especialmente por la referencia de Ulpiano a "personae possidentium aut in ius eorum succedentium", pues no parece corresponderse con la idea de que los contratos tendrían eficacia obligacional únicamente inter partes, con lo cual vincularían a las partes y, eventualmente, a sus herederos.

Para un sector de la doctrina ${ }^{53}$, la más antigua y correspondiente a la época de la caza de interpolaciones, esta mención sólo puede referirse a la persona del comprador y del vendedor, denominados "personae possidentium" por Ulpiano, ya que, al tratarse de un fundo provincial, no pueden ser propietarios; y de sus herederos, "in ius eorum seccedentium". Esta interpretación se basaría en el texto correspondiente a éste en las Basílicas, en el que se habla expresamente del comprador y de sus herederos como únicos sujetos vinculados por la cláusula. Asimismo, en la Glossa ad D. 8,3,14 pr., la mención a los sucesores se entiende hecha respecto

${ }^{51}$ Mohino Manrique, Ana, cit. (n. 2), pp. 262-263.

${ }^{52} \mathrm{El}$ recurso a la buena fe en el contrato de compraventa para sostener el carácter vinculante de determinadas cláusulas contractuales, a mediados del siglo I d. C., es empleado por la jurisprudencia no como una premisa para la ejecución del contrato según su letra, sino en relación con la valoración del resultado que las partes querían alcanzar cuando incluyeron la mencionada cláusula. DAJCZAK, Wojciech, cit. (n. 7), p. 83.

${ }^{53}$ Como por ejemplo, Perozzi, Silvio, cit. (n. 16), pp. 204-205; Solazzi, Siro, cit. (n. 18), pp. 27-28. 
de los sucesores a título universal ${ }^{54}$. Bártolo ${ }^{55}$ también contempla que la cláusula afecta únicamente al comprador y a sus herederos. Baldo ${ }^{56}$ considera, asimismo, que la cláusula sólo vincula a los sucesores del comprador a título universal y expresamente excluye que se dé un caso de obligación ambulatoria; en esta misma tendencia se pronuncia de Castro ${ }^{57}$. Esta interpretación que reconoce una eficacia restrictiva a la cláusula es mantenida, más adelante, por Savigny y Pernice ${ }^{58}$.

No obstante, esta interpretación no resulta satisfactoria si se compara con el contenido literal del fragmento de Ulpiano. No sin razón, Hallebeek ${ }^{59}$ hace hincapié en que el jurista, pudiendo haber mencionado únicamente al comprador, sólo menciona a los poseedores, del mismo modo que no habla de herederos, sino de sucesores, con lo que no excluye expresamente que los sucesores a título particular también se vieran afectados por la prohibición. Es más, si realmente Ulpiano hubiera estado pensando en el comprador y los herederos de las partes, hubiera sido más lógico que la conjunción utilizada en el texto hubiera sido et o vel, en lugar de aut-"personae possidentium aut in ius eorum succedentium"-. El problema de interpretar qué personas quedarían vinculadas por la cláusula se agrava todavía más, si tenemos en cuenta que el jurista acaba de advertir que no pudo constituirse una servidumbre en este supuesto por las razones expuestas anteriormente. Pero a pesar de esto, la lex venditionis o stipulationis parece afectar, a tenor del texto, no sólo al comprador, sino a los sucesivos poseedores del fundo Geroniano, con independencia de que sean sucesores a título universal o particular, por actos mortis causa o inter vivos.

No son pocas las fuentes jurisprudenciales que recogen supuestos en los que, con motivo de una compraventa, se incluye algún tipo de cláusula prohibitoria al comprador, que limita su derecho de propiedad sobre la cosa adquirida y que parecen dar lugar a una vinculación de carácter real que, de no ser respetada, puede suponer la resolución de la compraventa ${ }^{60}$. Así por ejemplo, este tipo de cláusulas

\footnotetext{
${ }^{54}$ Véase la gl. Succedentium: "Noli ita legere, personae succedentium, scilicet per legem stipulationis vel venditionis obligatur, orc.quia singulares successores personali obligatione non astringuntur. infra. ad Treb. l.i $S$ Si heredes. C. de hered. instit. l. quotiens [D. 36,1,1,16 Ulp., 3 fideic.; Iust. CI. 6,24,13 (a.529)]. Sed dicas obligantur personae in ius, scilicet hereditarium iure succedentium: obligantur quidem per legem venditionis, vel per legem stipulationis: \& collige ex hac l. quia si concedam tibi servitutem distingue an talem, per quam publicus usus non impeditur: \& tunc saltem ego vel mei heredes non debemus contravenire: ut supra tit. I [III] $l$. per fundum [D. 8,3,11 Cels., 27 dig.] an per quam impediatur: \& tunc etiam ego potero contravenire: ut supra de pactis. l. iuris gentium. S. si paciscar [D. 2,14,6,13 Ulp., 4 ed.]. Item not. Hic quod non debet quis contra factum suum venire, etiamsi de iure non tenet: ut supra de adopt. l. post mortem et tit. $i$ l. per fundum [D. 1,7,25 Ulp. 1 disp.]"; edición cit. (n. 44). Incorporamos entre corchetes la cita de los textos de la Compilación justinianea, así como alguna corrección al original.

${ }^{55}$ BARTOLO, In primam Digesti veteris partem commentaria (Torino, 1574), p. 189

${ }^{56}$ BALDO, In primam Digesti Veteris partem commentaria (Venezia, 1577), p. 329.

${ }^{57}$ De Castro, In primam Digesti veteris partem commentaria (Venezia, 1592), p. 176.

${ }^{58}$ Véanse: Biondi, Biondo, cit. (n. 24), p. 194; Hallebeek, Jan, cit. (n. 2), p. 40 y 41, n. 5 a 8.

${ }^{59}$ Hallebeek, Jan, cit. (n. 1), p. 45 ss.

${ }^{60}$ Téngase en cuenta lo que expresa Juliano en D. 18,5,5,1 (15 dig.): "Emptio nuda conventione dissolvitur, si res secuta non fuerit".
} 
aparecen frecuentemente en el caso de la compraventa de esclavos: dentro de este tipo de acuerdos prohibitorios, encontraríamos la cláusula ne manumittatur (D. 30,44,7, Ulp., 20 Sab.; D. 40,1,20,2, Pap., 10 resp.; Alex. CI. 4,57 [a. 222]; PS. 4,12,2); ne serva prostituatur (D. 2,4,10,1, Ulp., 5 ed.; D. 18,1,56 Paul., 50 ed.; D. 18,7,9 Paul., 5 quaest.; Alex. CI. 4,56,1 [a.223]); o ut servus exportetur (D. 18,7,1, Ulp., 32 ed.; D. 18,7,9, Paul., 5 quaest.; FV. 6 Pap., 3 resp.). En todos estos supuestos, la eficacia real de la cláusula derivaría de la realización de una mancipatio (lex dicta in mancipio) ${ }^{61}$.

Cláusulas que implican límites en la libertad de disponer sobre una cosa las encontramos también respecto de la hyphoteca o el pignus (D. 20,5,7,2, Marc., sing. ad form. hypoth.), en el caso de la societas, cuando se acordó por los socios que ésta no se dividiría (D. 10,3,14,3, Paul., 3 Plaut.; D. 17,2,16,1 Ulp., 30 Sab.) o en los testamentos, concretamente en el caso de los fideicomisos, en los que podría incluirse prohibiciones de enajenar respecto de determinados bienes, pensando en el beneficio de concretas personas, como los hijos, descendientes, libertos, etc. del causante (D. 30,114,14, Marc., 8 inst.). En todos estos supuestos, nos encontramos ante cláusulas (leges dictae) que no sólo afectan a los herederos de las partes, sino también a los terceros que adquieren la cosa. Como expresa $\mathrm{Kaser}^{62}$, estas disposiciones suponen una limitación del derecho de propiedad equivalente a las limitaciones que sólo podrían provenir de un legislador o sujeto similar -en el caso de los particulares, en principio, sólo podrían darse en el círculo de los iura in re aliena-. Respecto de estos casos, Jhering ${ }^{63}$ habla de "dinglich wirkende Beschränkungen im Bereich obligatorischer Verhältnisse (dinglich geschützte Obligation)", que constituirían casos especiales dentro de los derechos de servidumbre: "Sonderfälle aus dem Recht der Servituten".

Creemos que el texto de Ulpiano que nos ocupa contribuye a dar muestra de la clasicidad de la divisio perteneciente a este mismo jurista pacta in rem-pacta in personam, de D. 2,14,7,8 (Ulp., 4 ed.) $)^{64}$, y de las consecuencias prácticas de

\footnotetext{
${ }^{61}$ Kaser, Max, cit. (n. 2), pp. 97 ss. ; El MISMO, Das römische Privatrecht (Munich, 1971), I, p. 562; también en Rechtsgeschäftliche Verfügunsbeschränkungen im römischen Recht, en Festgabe für Johannes Sontis (Munich, 1977), pp. 11-31; KunKEL, Wolfgang, Römisches Recht (4a edicion, Berlín, 1987), pp. 321 ss.; Hausmaninger, H. - Selb, W. Römisches Recht (8a ed., 1997), p. 205 ss.; Mohino MarniQue, Ana, La eficacia real en las transacciones del comercio de esclavos (Madrid, 2008), p. 109 ss.

${ }^{62}$ KASER, Max, cit. (n. 61), pp. 12 ss. Para Kaser, siguiendo la opinión de Jhering: "Die Römer haben den Privaten die Macht zugestanden, bei bestimmten Geshäften durch einseitige Zusätze zu modifizieren, vor allem einzuschränken. Eine solche lex dicta, lex privata hat man, soweit sie von der staatlichen Ordnung zugelassen wird, als für den Geshäftsgegner ebenso verbindlich angesehen wie die lex publica und die anderen bindenden Quellen des römischen Staates”.

${ }^{63}$ Jhering, Rudolf von, Passive Wirkungen der Rechte, en Jahrbücher für die Dogmatik des heutigen römischen und deutschen Privatrechts, 10 (1871) pp. 387 ss. [http://dlib-zs.mpier.mpg.de/pdf/2084719/10/1871/ 20847191018710397.pdf]; Gesammelte Aufsätze, II, pp. 178 ss.; KASER, Max, cit. (n. 2), p. 98.

${ }^{64}$ Sobre la clasificación pacta in rem - pacta in personam (D. 2,14,7,8 Paul., 3 ed.), véanse: Melillo, Generoso, "Pacta in rem, pacta in personam": una divisio classica?, en Sodalitas. Scritti Guarino (Napoli, 1984), III, pp. 1.459 ss.; El MISmO, "Contrahere, pascici, transigere”. Contributi
} 
su vigencia, pues para Ulpiano, el pacto añadido a la compraventa del fundo Geroniano, en virtud del cual se prohíbe la pesca del atún, es un pacto a favor del fundo Botriano, de modo que su naturaleza es la de un pactum in rem:

La cuestión de que un pacto sea considerado in rem o in personam no es baladí, pues en el caso de los pacta in rem, se asegura la transmisibilidad mortis causa o inter vivos de las situaciones del causante derivadas de dicho pacto. El pacto a través del cual se prohíbe la práctica de la pesca en el fundo Geroniano es un pacto que se concluye, no en beneficio exclusivo del vendedor, sino en beneficio del fundo Botriano, claramente en el texto se expresa que la prohibición afecta a la pesca que se realiza "contra eum". En tanto que puede entenderse que el pacto concluido por el vendedor es un pacto in rem, éste afectará a cualquier sucesor del comprador, ya tenga lugar la sucesión por actos inter vivos o mortis causa.

Esta misma idea es la que refleja Ulpiano en D. 43,20,1,43 (Ulp., 70 ed.): “Et datur interdum praediis, interdum personis. Quod praediis datur, persona extincta non extinguitur: quod datur personis, cum personis amittitur ideoque neque ad alium dominum praediorum neque ad heredem vel qualemcumque successorem transit".

En el texto, se habla de la concesión de conducir agua desde un depósito, arroyo o lugar público, en relación con la cuestión de si dichas conducciones quedan protegidas por el pretor a través de interdictos, al igual que sucede con las protección interdictal, en el caso de conducción de agua perenne. Ulpiano distingue si la concesión se realiza a favor del fundo "datur interdum praediis" o a favor de una persona, "datur interdum personis". En el caso que la facultad de conducir agua se da a favor de una persona, cuando ésta desaparece o enajena el fundo al que conducía el agua, dejan de disponer de este derecho el nuevo propietario del fundo, o cualquier sucesor de esa persona: "neque ad alium dominum praediorum neque ad heredem vel qualemcumque successorem transit”. Es decir, dicha facultad es intransmisible. En cambio, cuando la facultad de conducir agua se concede a favor de un fundo y no de su titular, a la muerte del titular, no se extingue dicha facultad, sino que se transmite a los sucesivos propietarios de ese fundo. Ulpiano determina, por tanto, la transmisibilidad del derecho de conducir agua en función de que éste se conceda en beneficio de una persona (pactum in personam) o en beneficio del fundo (pactum in rem). En el mismo sentido parecen expresarse Escévola en D. 8,5,20,1 (Scaev., 4 dig.) y Paulo en D. 8,3,37 (Paul., 3 resp.).

La determinación de si el beneficio se concede a una persona o a un fundo dependería, como indica Escévola en D. 8,5,20,1, del id quod actum est: "id observandum, quod actum inter contrahentes esset" ${ }^{65} \mathrm{y}$, en definitiva, de la interpretación de cuál es la voluntad de las partes, a lo que parece atender Ulpiano, partiendo de la buena fe del contrato de compraventa, para expresar que la prohibición de la pesca de atún afecta al comprador y a cualquier sucesor de éste, no sólo a sus herederos. Pues efectivamente, cuando el vendedor incluyó la cláusula prohibitoria, lo hizo en beneficio del fundo que retenía y con independencia de quien pudiera poseer el

allo studio del negozio bilaterale romano (Milano, 1994), pp. 226 ss.; Mannino, Vincenzo, Sulla trasmissibilità dell'exceptio pacti, en Labeo, 40 (1994) 2, pp. 170 ss.

${ }^{65}$ Babusiaux, Ulrike, "Id quod actum est". Zur Ermittlung des Parteienswillens im klassischen römischen Zivilprozeß (Munich, 2006), pp. 133 ss. y pp. 200-201. 
fundo vecino, debido a ello, su intención primera era constituir una servidumbre predial. Obviamente la lex venditionis o stipulationis no da lugar, en este caso, a la constitución de una servidumbre, sino a una obligación, como se indica de forma expresa en el texto "per stipulationis vel venditionis legem obligantur" ${ }^{66}$, que sin embargo ha de afectar a cualquiera que posea el fundo Geroniano, dando lugar a una obligación ambulatoria ${ }^{67}$.

Este texto sirve de muestra de cómo los pactos podían dar lugar a las más diversas situaciones jurídicas y cómo, en este supuesto, el pacto concluido en ocasión de una compraventa se escapa de la eficacia limitada que se atribuye, por regla general, a los contratos.

Así pues, pese a que no pudo constituirse una servidumbre predial pactionibus et stipulationibus, como habrían querido las partes inicialmente, Ulpiano considera que la prohibición de pescar atún debe mantenerse en virtud de la buena fe contractual y, debido a ello, cualquier sujeto que adquiera el fundo Geroniano deberá respetar dicha prohibición.

\section{BIBLIOGRAFÍA}

Albanese, Bernardo, Gli atti negoziali nel diritto privato romano (Palermo, 1982).

BABUSIAUX, Ulrike, "Id quod actum est". Zur Ermittlung des Parteienswillens im klassischen römischen Zivilprozeß (Munich, 2006).

BALDO, In primam Digesti Veteris partem commentaria (Venezia, 1577), p. 329.

BARTOLO, In primam Digesti veteris partem commentaria (Torino, 1574), p. 189.

BASILE, Raffaele, Pactionibus et stipulationibus id efficere, en "Fides, humanitas, ius". Studii in onore di Luigi Labruna (Napoli, 2007), I.

BeHREnds, Okko y otros, Corpus iuris civilis. Text und Übersetzung (Aufder von Theodor Mommsen und Paul Krüger besorgten Textausgaben) (Heidelberg, 1990), II.

BIONDI, Biondo, Le servitù prediali nel diritto romano (Milano, 1969).

BlÁzQuez MARTínez, José $\mathrm{M}^{\mathrm{a}}$, La pesca en la antigüedad y sus factores económicos, en Antigua. Historia y arqueología de las civilizaciones. Portal temático de la Biblioteca Virtual Miguel de Cervantes, pp. 7 ss. [http://www.cervantesvirtual.com/Portal/ Antigua/index.shtml].

Claudius Aelianus, De natura animalium.

Corbino, Alessandro, s.v. “Servitü”, en ED. (Milano, 1990), XLII.

DAJCZAK, Wojciech, L'uso della bona fides nei giuristi romani classici per la valutazione del valore vincolante degli accordi contrattuali, en RIDA., 44 (1997), pp. 81 ss. [http://www2.ulg.ac.be/vinitor/rida/1997/dajczak2.pdf].

${ }^{66}$ Contrariamente, que el texto hable de obligatio no sería óbice, según Finkenauer, para entender que existe una servidumbre, pues en definitiva lo que importaría sería que la prohibición de pescar atún se transmite a cualquier sucesor del comprador. Aun cuando Ulpiano claramente expresa que no se ha contituido una servidumbre en este caso ("servitus imponi privata lege non potest"). FinKENAUER, Thomas, cit. (n. 1), p. 381.

${ }^{67}$ En el mismo sentido, aunque partiendo de la constitución de una servidumbre pactionibus et stipulationibus, que sólo puede dar lugar a una obligación ambulatoria, Provera, Giuseppe, cit. (n. 1), pp. 17 ss.; Hallebeek, Jan, cit. (n. 1), pp. 45-46. 
De Castro, In primam Digesti veteris partem commentaria (Venezia, 1592), p. 176.

FInKENAUER, Thomas, Vererblichkeit und Drittwirkungen der Stipulatio im klassischen römischen Recht (Tübingen, 2010).

Fiorentini, Mario, Fiumi e mari nell'esperienza giuridica romana. Profili di tutela processuale e di inquadramento sistematico (Milano, 2003).

FioRENTINI, Mario, Sulla rilevanza economica e giuridica delle ville marittime durante la Reppublica e l'Impero, en Index, 24 (1996).

Franciosi, Gennaro, cit. (n. 2), p. 102; Purpura, Gianfranco, cit. (n. 2), p. 2.164; Mohino Manrique, Ana, cit. (n. 2) , p. 252.

Franciosi, Gennaro, Il divieto della piscatio thynnaria: un'altra servitù prediale?, en RIDA., 49 (2002).

Frezza, Paolo, Appunti esegetici in tema di modi pretori di costituzione di usufrutto e delle servitú prediali, en Studi economico-giuridici dell'Università di Cagliari, 22 (1934).

García Quintas, Ma de las Mercedes, El mar desde la perspectiva jurisprudencial romana, en $R G D R ., 15$ (2010).

García Vargas, Enrique, Pesca, sal y salazones, en Treballs del Museu Arqueològic d'Eivissa i Formentera, 47 (2001): actas del congreso De la mar y de la tierra: producciones y productos fenicio-púnicos. XV Jornadas de Arqueología fenicio-púnica (Eivissa, 2000).

GiUfFrè, Vincenzo, L'emersione dei iura in re aliena ed il dogma del numero chiuso (Napoli, 1992).

Gozalbes Cravioto, Enrique, La pesca del atún en la antigüedad, en Aljaranda. Revista de Estudios Tarifeños. Ayuntamiento de Tarifa, 34 (1999), p. 3 [http://www. tarifaweb.com/aljaranda/num34/art5.htm].

Gozlan, Suzanne, Les mosaïques de la maison d'Asinius Rufinus à Acholla (Tunisie), en las actas de Mosä̈que Gréco-romaine (Bath, 1994), V.

Grosso, Giuseppe, Le servitù prediali nel diritto romano (Turín, 1969).\}

Hallebeek, Jan, Legal Problems Concerning a Draught of Tunny. Exegesis of D.8.4.13 pr., en TR., 55 (1987).

Hausmaninger, H. - Selb, W. Römisches Recht (8a ed., 1997).

Honoré, Anthony, Ulpian (Oxford, 1982).

Honoré, Anthony, voz "Domicio Ulpiano", en Juristas universales (Madrid-Barcelona, 2004), I: Juristas antiguos.

JHering, Rudolf von, Passive Wirkungen der Rechte, en Jahrbücher für die Dogmatik des heutigen römischen und deutschen Privatrechts, 10 (1871) [http://dlib-zs.mpier.mpg.de/pdf/2084719/10/1871/ 20847191018710397.pdf].

KASER, Max, Das römische Privatrecht (Munich, 1971), I.

KASER, Max, Der Privatrechtsakt in der römischen Rechtsquellenlehre, en Festschrift für Franz Wieacker zum 70. Geburtstag (Göttingen, 1978).

KASER, Max, Rechtsgeschäftliche Verfügunsbeschränkungen im römischen Recht, en Festgabe für Johannes Sontis (Munich, 1977).

KNÜTEL, Rolf, s.v. "Ulpianus, Domitius", en Juristen. Ein biographisches Lexikon von der Antike bis zum 20. Jh. (Munich, 2001).

KRÜGER, Hugo, Die prätorische Servitut (Münster, 1911).

KunKel, Wolfgang, Die römischen Juristen: Herkunft und soziale Stellung (reed. Köln, 2001). 
KunKel, Wolfgang, Römisches Recht (4a edicion, Berlín, 1987).

LA Rosa, Franca, "Deducere usum fructum, excipere servitutem", en Studi in onore di Cesare Sanfilippo (Milano, 1987), VII.

La Rosa, Franca, Pactionibus et stipulationibus, Labeo, 40 (1994) 1.

LENEL, Otto, Palingenesia iuris civilis, II.

Liaño Rivera, M. La pesca del atún. Salir por la vía de Tarifa, en Aljaranda. Revista de estudios tarifeños. Ayuntamiento de Tarifa, 26, (1997), p. 1 [http://www.tarifaweb. com/aljaranda/num26/art1.htm].

LieBs, Dieter, “Ulpiani opinionum libri VI”, en TR., 41 (1973).

Mannino, Vincenzo, Sulla trasmissibilità dell'exceptio pacti, en Labeo, 40 (1994) 2.

Maschi, Carlo Alberto, Contributi allo studio delle servitù pretorie, BIDR, 41 (1939).

Melillo, Generoso, "Contrahere, pascici, transigere". Contributi allo studio del negozio bilaterale romano (Milano, 1994).

Melillo, Generoso, "Pacta in rem, pacta in personam": una divisio classica?, en Sodalitas. Scritti Guarino (Napoli, 1984), III.

Mohino Manrique, Ana, Pactos en el contrato de compraventa en interés del vendedor (Madrid, 2006).

Mohino Marnique, Ana, La eficacia real en las transacciones del comercio de esclavos (Madrid, 2008).

Möller, Cosima, Entwicklungs-geschichte, Funktion und Struktur der grundstückvermittelten Privatrechtsverhältnisse im römischen Recht. Mit einem Ausblik auf die Rezeptionsgeschichte und das BGB (Göttingen, 2010).

OpPIANus de Corycus, Halieutica.

Perozzi, Silvio, I modi pretorii d'acquisto delle servitù, en Rivista italiana per le scienze giuridiche, 23 (1897) [= Scritti giuridici, II (Milano, 1948), II].

Provera, Giuseppe, Servitù prediali ed obbligazioni propter rem, en Studi in onore di Edoardo Volterra (Milano, 1971), II [http://www.ledonline.it/rivistadirittoromano/ allegatiproveraservitu.pdf].

Purpura, Gianfranco, Servitus thynnos non piscandi (D.8.4.13 pr.), en D’IPPolito, Federico Maria (editor), Scritti per Gennaro Franciosi (Napoli, 2007), III.

Randazzo, Salvo, "Servitus iure imposita". Destinazione del padre di famiglia e costituzione "ipso iure" della servitù, en RDR., 2 (2002), pp. 289 ss. [disponible en http:// www.ledonline.it/rivistadirittoromano/allegati/dirittoromano02randazzo.pdf].

Randazzo, Salvo, Leges mancipii. Contributo allo studio dei limiti di rilevanza dell'accordo negli atti formali di alienazione (Milano, 1998).

SANTAluCia, Bernardo, I libri “opinionum” di Ulpiano (Milano, 1971).

SAntos Rojo, Cristina, La reserva de servidumbre (Valencia, 2001).

Schulz, Fritz, Storia della giurisprudenza romana (Florencia, 1968).

Solazzi, Siro, La tutela e il possesso delle servitù prediali (Napoli, 1949).

SolazzI, Siro, Requisiti e modi di costituzione delle servitù prediali (Napoli, 1947).

SolAzZI, Siro, Requisiti e modi di costituzione delle servitù prediali (Napoli, 1947).

SolazzI, Siro, Specie ed estinzione delle servitù prediali (Napoli, 1948).

SolazzI, Siro, Stipulazioni di servitù prediali, en Iura, 5 (1954).

Talamanca, Mario, Istituzioni de diritto romano (Milano, 1990).

Talamanca, Mario, Pubblicazioni pervenute alla Direzione, en BIDR., 91 (1998).

WACKE, Andreas, Wettbewerbsfreiheit und Konkurrenzverbotklauseln im antiken und modernen Recht, en ZSS., 99 (1982). 
Zuccotтi, Ferdinando, Sulla tutela processuale delle servitù cosidette pretorie, en Atti del Convegno "Processo civile e processo penale nell'esperienza giuridica del mondo antico", Siena, Certosa di Pontignano, 13-15 decembre 2001, pp. 182-183 [http:// www.ledonline.it/rivistadirittoromano/allegati/attipontignanozuccotti.pdf]. 
